\title{
Dependency of magnetocardiographically determined fetal cardiac time intervals on gestational age, gender and postnatal biometrics in healthy pregnancies
}

\author{
Peter van Leeuwen*1, Silke Lange ${ }^{1}$, Anita Klein ${ }^{1}$, Daniel Geue ${ }^{1}$ and \\ Dietrich HW Grönemeyer ${ }^{2}$
}

\author{
Address: ${ }^{1}$ Department of Biomagnetism, Research and Development Center for Microtherapy (EFMT), Universitätsstr. 142, 44799 Bochum, \\ Germany and ${ }^{2}$ Grönemeyer Institute for Microtherapy, University of Witten/Herdecke, Universitätsstr. 142, 44799 Bochum, Germany \\ Email: Peter van Leeuwen* - petervl@microtherapy.de; Silke Lange - lange@microtherapy.de; Anita Klein - klein@microtherapy.de; \\ Daniel Geue-geue@microtherapy.de; Dietrich HW Grönemeyer -dg@microtherapy.de \\ * Corresponding author
}

Published: 02 April 2004

BMC Pregnancy and Childbirth 2004, 4:6
Received: 30 January 2004

Accepted: 02 April 2004

This article is available from: http://www.biomedcentral.com/I47/-2393/4/6

(c) 2004 van Leeuwen et al; licensee BioMed Central Ltd. This is an Open Access article: verbatim copying and redistribution of this article are permitted in all media for any purpose, provided this notice is preserved along with the article's original URL.

\begin{abstract}
Background: Magnetocardiography enables the precise determination of fetal cardiac time intervals (CTI) as early as the second trimester of pregnancy. It has been shown that fetal CTI change in course of gestation. The aim of this work was to investigate the dependency of fetal CTI on gestational age, gender and postnatal biometric data in a substantial sample of subjects during normal pregnancy.
\end{abstract}

Methods: A total of 230 fetal magnetocardiograms were obtained in 47 healthy fetuses between the $15^{\text {th }}$ and $42^{\text {nd }}$ week of gestation. In each recording, after subtraction of the maternal cardiac artifact and the identification of fetal beats, fetal PQRST courses were signal averaged. On the basis of therein detected wave onsets and ends, the following CTI were determined: P wave, PR interval, $\mathrm{PQ}$ interval, QRS complex, ST segment, T wave, QT and QTc interval. Using regression analysis, the dependency of the CTI were examined with respect to gestational age, gender and postnatal biometric data.

Results: Atrioventricular conduction and ventricular depolarization times could be determined dependably whereas the $T$ wave was often difficult to detect. Linear and nonlinear regression analysis established strong dependency on age for the $\mathrm{P}$ wave and QRS complex $\left(r^{2}=0.67, p<\right.$ $0.00 \mathrm{I}$ and $\left.r^{2}=0.66, p<0.00 \mathrm{I}\right)$ as well as an identifiable trend for the PR and PQ intervals $\left(r^{2}=0.2 \mathrm{I}\right.$, $p<0.00 \mathrm{I}$ and $r^{2}=0.13, p<0.00 \mathrm{I}$ ). Gender differences were found only for the QRS complex from the 3 I st $^{\text {seek onward }}(p<0.05)$. The influence on the $P$ wave or QRS complex of biometric data, collected in a subgroup in whom recordings were available within I week of birth, did not display statistical significance.

Conclusion: We conclude that I) from approximately the $18^{\text {th }}$ week to term, fetal CTI which quantify depolarization times can be reliably determined using magnetocardiography, 2) the $P$ wave and QRS complex duration show a high dependency on age which to a large part reflects fetal growth and 3) fetal gender plays a role in QRS complex duration in the third trimester. Fetal development is thus in part reflected in the CTI and may be useful in the identification of intrauterine growth retardation. 


\section{Background}

In recent years it has been shown that fetal magnetocardiography (FMCG) is suited for the determination of fetal cardiac time intervals (CTI) [1-7]. Various intervals reflecting atrial and ventricular de- and repolarization times have been identified on the basis of the waveforms of the P wave, the PR interval, the QRS complex, the T wave and others. These studies all examine the QRS complex and most present the P wave or PR interval but none report on all relevant CTI. The durations of the individual CTI studied tend to cover a wide range of values. In particular with respect to the $\mathrm{P}$ wave and $\mathrm{QRS}$ complex, one of the primary reasons for this is the dependency on the gestational age of the fetus. This is presumed to be associated with the increase in cardiac tissue mass and dimensions concomitant with fetal growth [8]. Also, it has been shown that the QRS complex may be influenced by the gender of the fetus [9]. Other CTI, such as those involving the T wave, display a high degree of variance because the onset and end of this wave can often not be determined unambiguously due to its low amplitude, low frequency nature.

Furthermore, it has been shown that there are systematic differences in CTI duration between the various groups active in this field [8]. One must thus presume that the equipment and procedures used in data acquisition and evaluation play a role in contributing to the distribution of the data. In previous work, we have examined factors such as biomagnetometer sensor configuration and observer reproducibility and have been able to show that the number of registration channels and signal-to-noise characteristics affect reliability in the determination of the CTI [10]. The same work showed, on the other hand, that inter-observer reproducibility was high when appropriate criteria in the determination of waveform boundaries were maintained. On the whole, there is consensus between most investigators that, in order to produce comparable results, certain guidelines should be followed in data acquisition, evaluation and documentation [11].

Various possibilities for the clinical application of FMCG have been proposed. With respect to CTI it has been suggested that their utility may lie in the identification of fetuses with arrhythmias [12-14], congenital heart defects $[15,16]$ and intrauterine growth retardation (IUGR) $[4,17]$. With IUGR in particular, the expectation is that, all other things being equal, the duration of the CTI will be shorter in compromised fetuses. Thus, in order to optimize the potential discriminatory power of the CTI, pertinent factors, not associated with disease states, which may influence CTI duration must be identified and their effect estimated. The aim of this work was to precisely determine all relevant CTI in a relatively large group of healthy fetuses and to investigate the effect of gestational age and gender using regression analysis. The results might serve as reference values for future work dealing with pathological fetal conditions. Furthermore, a preliminary attempt to associate CTI duration with postnatal biometric data was undertaken.

\section{Methods}

The subjects in this study included 43 women in 47 healthy pregnancies $(32 \pm 3$ years of age) in which fetal gender was documented. Subjects excluded from this study were those in whom the fetuses exhibited arrhythmic beats [13], IUGR, congenital heart disease or in which maternal hypertension, diabetes or nicotine abuse was present. Of the included subjects, 20 were para 0, 23 para I and 4 para II. Twenty-eight (60\%) of the fetuses were male, 19 (40\%) were female. We recorded 255 FMCGs between the $12^{\text {th }}$ and $42^{\text {nd }}$ week of gestation, of which 230 displayed sufficient signal quality to enable evaluation. All of the 25 recordings which could not be evaluated were prior to the $20^{\text {th }}$ week, the success rates between the $12^{\text {th }}$ and $19^{\text {th }}$ week being $0 \%, 0 \%, 0 \%, 17 \%, 29 \%, 17 \%$, $80 \%$ and $90 \%$ (Fig. 1). Of the remaining 230 available FMCGs between the $15^{\text {th }}$ and $42^{\text {nd }}$ week of gestation, we obtained on average $4.9 \pm 4.3$ per fetus (range $1-23$ ). In the period from the $18^{\text {th }}$ to the $39^{\text {th }}$ week, the number of recordings per week of gestation lay between 6 and 14 $(10.0 \pm 2.3)$, before the $18^{\text {th }}$ and after the $39^{\text {th }}$ week the number of recordings was between one and three per week of gestation (Fig. 1). Of all evaluated recordings, 116 (50.4\%) were performed in male fetuses, 114 (49.6\%) in female. The study is in compliance with the Helsinki Declaration, was approved by the local ethics committee and all mothers gave written informed consent.

\section{Data acquisition}

FMCGs were acquired using a 61 channel biomagnetometer (Magnes 1300C, 4D Neuroimaging, San Diego) in 162 cases. The sensing channels are arranged as 4 concentric rings around a central channel with an overall diameter of $32.4 \mathrm{~cm}$ and an area of coverage of ca. $800 \mathrm{~cm}^{2}$. A configuration of 11 reference coils is used to detect ambient noise and intrinsic system noise is given as being less than $10 \mathrm{fT} / \mathrm{Hz}^{1 / 2}$ (fT: femtotesla) for frequencies $>5 \mathrm{~Hz}$. A further 68 FMCGs were recorded using a 37 channel system (Krenikon, Siemens, Erlangen). This system consists of sensing coils configured as 1 st order gradiometers (baseline $7 \mathrm{~cm}$ ) in a hexagonal grid with an overall diameter of $19 \mathrm{~cm}$ (area of coverage: ca. $283 \mathrm{~cm}^{2}$ ). System noise is given as less than $30 \mathrm{fT} / \mathrm{Hz}^{1 / 2}$ for frequencies $>2 \mathrm{~Hz}$ and $10 \mathrm{fT} / \mathrm{Hz}^{1 / 2}$ for frequencies $>10 \mathrm{~Hz}$. Previous work has shown that the estimation of CTI is comparable for these two systems [10]. For data acquisition the mothers were in a supine position with the biomagnetometer placed as close to the abdomen as possible while avoiding skin contact. The 61 channel system was positioned symmetrically over the abdomen, the lower rim over the pubis and the 


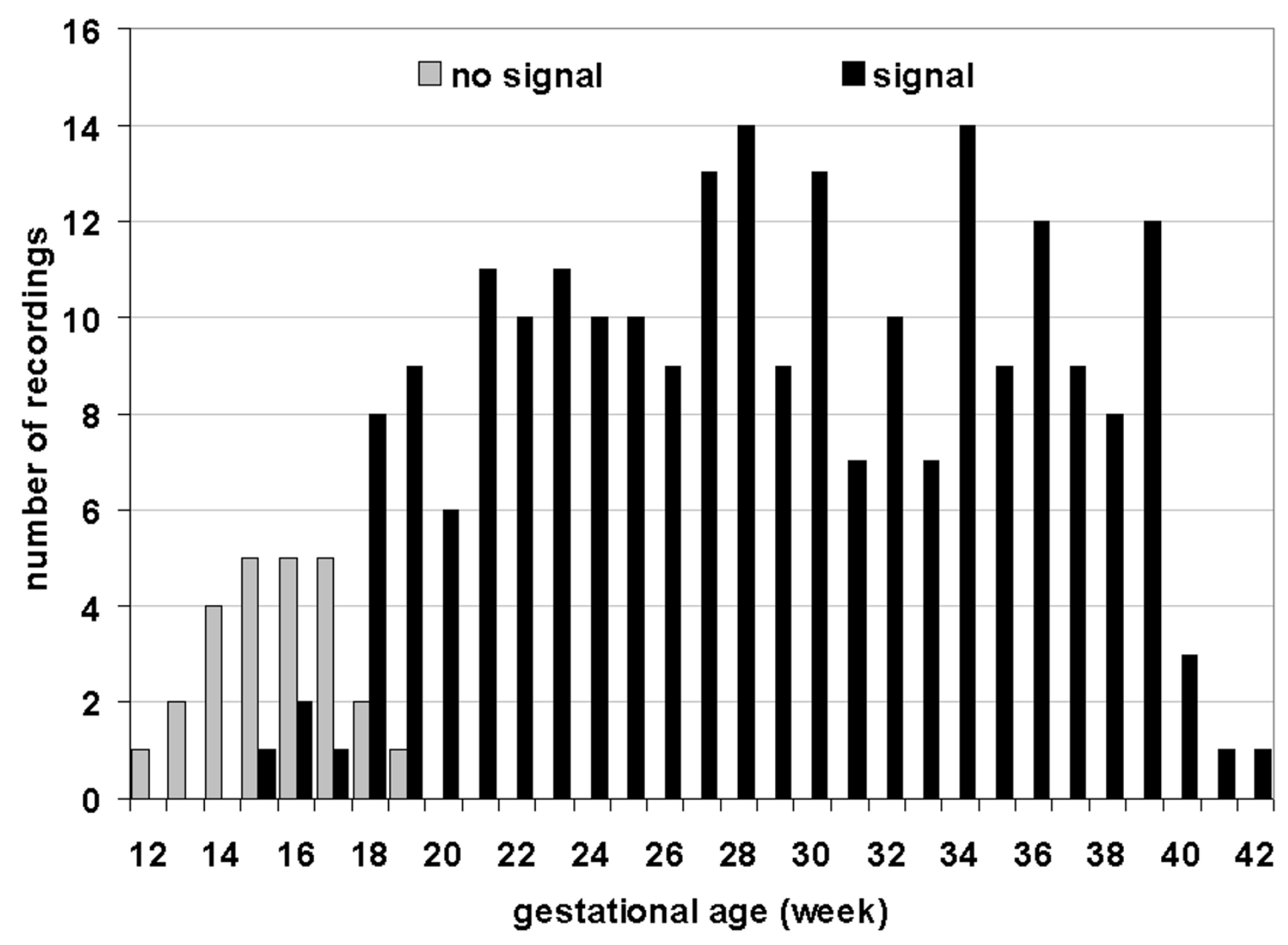

Figure I

Number of recordings Number of FMCG recordings obtained between the $12^{\text {th }}$ and $42^{\text {nd }}$ week of gestation. Viable recordings were available as early as the $15^{\text {th }}$ week and, from the $20^{\text {th }}$ week on, all recordings could be evaluated (no signal $=$ signal-tonoise ratio too low for the identification of fetal QRS complexes; signal = sufficient signal quality for evaluation).

upper rim approximately over the xyphoid. The smaller 37 channel system was positioned such that channels at the center of the sensor displayed high amplitude fetal QRS complexes. Data were usually recorded for 5 minutes at a sampling rate of $1 \mathrm{kHz}$ and with a bandpass of 1-200 Hz. To reduce the effects of external noise, all measurements were performed in a standard shielded room (AK3b, Vacuumschmelze, Hanau). Recordings were generally performed between $10 \mathrm{AM}$ and 4 PM.

\section{Data analysis}

In each set of data, maternal heart beats were identified by correlation to a maternal QRS signal template and the maternal PQRST signal components were then digitally averaged and subsequently subtracted from the signal traces. In the resulting traces, fetal beats were similarly identified on the basis of a representative fetal QRS signal template. Fetal PQRST courses to be averaged were chosen on the basis of a good correlation $(r \geq 0.90)$ to the template (generally»300 beats). In the averaged data, the onsets (or endpoints) of the P wave, QRS complex and T wave were defined as the visually identifiable first (or last) deviation from the signal's baseline in any one channel out of all channels available for evaluation [11]. Due to the low amplitude of the T wave and possible DC drift, its onsets and end were determined on the basis of identifiable changes in amplitude at appropriate latencies. All channels were displayed individually avoiding overlap and within a fixed time window $(20 \mathrm{~ms} / \mathrm{cm})$ and a defined range of amplitudes $(0.1-0.5 \mathrm{pT} / \mathrm{cm}$ for the $\mathrm{P}$ and 


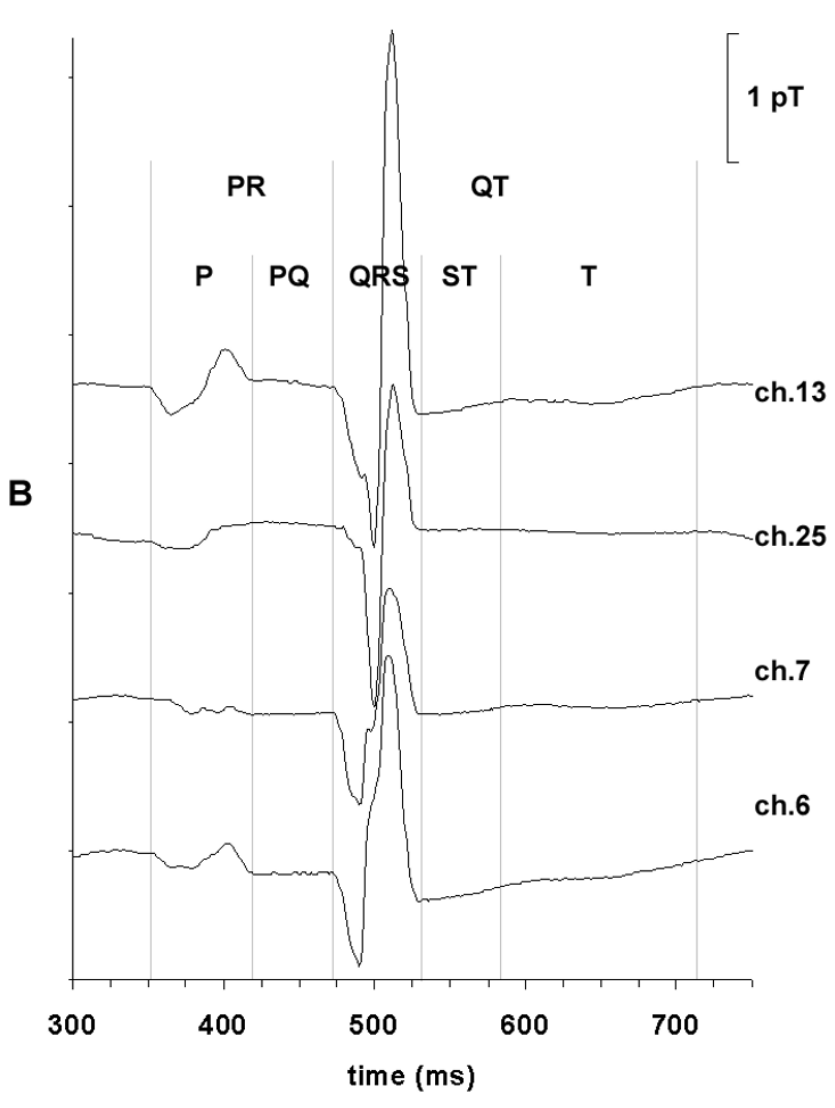

Figure 2

Averaged FMCG signal FMCG signal traces from 4 selected channels of the averaged data of a recording performed in the 39th week of gestation. The vertical lines show how the signal onsets and ends were set and used to determine the cardiac time intervals. ( $B=$ magnetic field strength)

T wave, 0.5-1.0 $\mathrm{pT} / \mathrm{cm}$ for the QRS complex). The onsets and ends were independently determined by two experienced investigators and their results were compared. The final value for each time point was set accordingly: in cases of differences $>2 \mathrm{~ms}$ both investigators reevaluated and corrected the results, otherwise the results were averaged. These time points were then used to calculate the duration of the CTI. We determined the consecutive, non-overlapping (disjunct) intervals as follows: $\mathrm{P}$ wave $=P_{\text {end }}-P_{\text {onset }}$ PQ interval $=$ QRS $_{\text {onset }}-P_{\text {end }}$ QRS complex $=\mathrm{QRS}_{\text {end }}-\mathrm{QRS}_{\text {onset }}$ ST segment $=\mathrm{T}_{\text {onset }}-\mathrm{QRS}_{\text {end }}$ and $\mathrm{T}$ wave $=\mathrm{T}_{\text {end }}-\mathrm{T}_{\text {onset }}$. Furthermore, the following composite CTI were determined: $P R$ interval $=\mathrm{P}$ wave $+\mathrm{PQ}$ interval and QT interval $=$ QRS complex + ST segment + T wave (see Figure 2). Also, the rate corrected QT interval (QTc) was calculated according to Bazett's formula [18]. In some traces, signal quality did not permit the unequivocal iden- tification of the timing of an event and the corresponding CTI were not determined.

The dependency on gestational age was assessed for the CTI over all data sets using regression analysis. The same dependency in the male and female subgroups was similarly examined and compared. In order to examine the relationship between postnatal biometric data (birth weight, head circumference and crown-heel length) and the CTI, we examined the dependency of those intervals which clearly correlated to development. For this, only data sets in which the CTI were determined within the last 7 prepartum days were considered.

\section{Statistics}

Values describing the subject and FMCG acquisition groups were expressed as means \pm standard deviation. Simple linear as well as nonlinear regression was used to estimate the parameters governing the change of the CTI over gestational age. For all regressions, the dependencies due to repeated measurements were considered by performing a robust regression using a modified Huber/ White/Sandwich estimator of variance [19]. For any interval, the model that demonstrated the best fit, based on the coefficient of determination, was chosen as most appropriate. For those intervals displaying a clear dependency on gestational age with respect to the best fitting model, estimated values and $90 \%$ prediction intervals were calculated on a weekly basis. For those intervals lacking a clear dependency, measures of location were calculated overall. To examine the differences between male and female CTI at a specific week of gestation, all values of each gender were projected to that week on the basis of each sex's best fitting model and the projected group values compared using Mann-Whitney U test. The dependency of the CTI on biometric parameters was examined using simple linear regression. Statistical significance was assumed at a level of 0.05 .

\section{Results}

Unambiguous identification of the waveform onsets and offsets was possible in virtually all of the fetal atrial and ventricular depolarization signals, with $99 \%$ of the $P$ wave and PQ interval durations as well as $100 \%$ of the QRS complex durations available for evaluation. The onsets and ends of ventricular repolarization were markedly more difficult to identify. The determination rates of $94 \%$ for the $\mathrm{T}$ wave and the ST segment durations were achieved only by meticulous examination of the waveforms [10]. It follows that the results must be viewed with caution as the low amplitude, low frequency character of the T wave involved a higher risk of error. 


\section{Gestational age}

The CTI showed varying dependency on gestational age: Figure 3 shows that, of the contiguous, disjunct intervals, in particular the duration of the $P$ wave and QRS complex increased clearly over time whereas the PQ interval showed a slight tendency to decrease with age. The ST segment and $\mathrm{T}$ wave duration demonstrated a wide spread without a clear trend. The composite intervals were characterized by a modest positive relationship to week of gestation, primarily reflecting the influence of the depolarization times. Regression analysis confirmed the visual impression (Table 1 ) with statistically significant slopes for all intervals except the ST segment and the T wave. The model fits were especially good for the $\mathrm{P}$ wave and the QRS complex. Implementing non-linear models improved the fit for the PQ and PR interval as well as the QRS complex.

For the intervals showing the clearest changes over time ( $P$ wave and QRS complex) we calculated various measures of location on the basis of the best fitting models for each gestational week from the $17^{\text {th }}$ to the $42^{\text {nd }}$ (see Table 2, Table 3). Although the dependency on age was not as pronounced, we did the same for the PR and PQ intervals (Table 2). For the remaining intervals, the scatter of the data was too large to permit a meaningful differentiation according to week of gestation (see Fig. 3 ) and the numerical description of the data is given without reference to gestational age (Table 4).

\section{Gender}

With respect to fetal gender, most intervals showed no obvious differences in duration (Figure 3). However, the duration of the QRS complex seemed to be shorter in the females, particularly after the $30^{\text {th }}$ week of gestation. As this suggested a different development between the two sexes, we examined the dependency on age separately for these subgroups using different models. We found that the best fitting model for the males was logarithmic $\left(\ln (\mathrm{QRS})=0.594^{*} \ln (\right.$ week $\left.)+1.852, r^{2}=0.64, p<0.001\right)$ and hyperbolic for females $\left(\mathrm{QRS}=-646^{*}(1 /\right.$ week $)+68, r^{2}$ $=0.71, p<0.001)$. Using these respective models to adjust for different weeks of gestation showed that QRS duration differed significantly between gender from the $31^{\text {st }}$ week onward. We thus used these model to calculate values for the QRS complex separately for male and female subjects (Table 3).

\section{Biometric data}

As the P wave and QRS complex showed a distinct relationship to gestational age reflecting fetal growth, we assumed that an association to postpartum biometric parameters might exist. We therefore examined the duration of these two intervals with respect to birth weight, head circumference and crown-heel length in those fetuses in whom MCG recording were obtained within 7 days of parturition. None of the intervals showed a statistically significant relationship to the biometric data (Table $5)$. However a trend was apparent for head circumference, especially with respect to the QRS complex.

\section{Discussion}

The main findings of this study are that, of the time intervals that compose fetal cardiac electrophysiological activity, atrial and ventricular depolarization times clearly increase in the second and third trimester of pregnancy and that these changes are in part dependent on gender. Furthermore, ventricular repolarization duration and intervals not involving depolarization do not demonstrate these dependencies.

Our results are in general agreement with those in Stinstra et al [8] which included a large amount of data contributed by a number of laboratories. However that study had the difficulty that the data showed systematic differences between the data of the contributing centers. There may be various reasons for this bias resulting from different recording and evaluation techniques [10]. The work presented here largely avoids these technical difficulties and we may thus expect the observed trends and variance to reflect more closely the physiological factors involved.

A further difficulty in comparing the published results of different groups is that the documentation of the changes during pregnancy takes on various forms. The reports may include mean and extreme values averaged over $\geq 4$ week periods [1,3,5-7] or regression-based estimated values $[8,17,20]$. The data may be plotted with or without confidence intervals $[4-8,17,20]$. In some of the work, estimations of age dependency are given, based on correlation and/or regression analysis $[1,4-8,17,20]$. In this report we have given most of this information on all CTI we examined and we have included a week by week descriptive analysis for those CTI displaying a distinct dependency on age, namely the $\mathrm{P}$ wave, PR and PQ interval as well as the QRS complex. Considering the size of the study population and the relatively consistent recording and evaluation procedures applied in accordance with accepted standards [11], these values may serve as reference values.

We did not consider it appropriate to take the effect of gestational age into account for the QT and QTc intervals although they showed a statistically significant slope in the regression analysis. These intervals, as well as the ST segment and $\mathrm{T}$ wave, were characterized by low coefficients of determination $(<0.08)$, indicating that the effect of age was minimal with a wide spread of data at any specific gestational age and a large data overlap over 

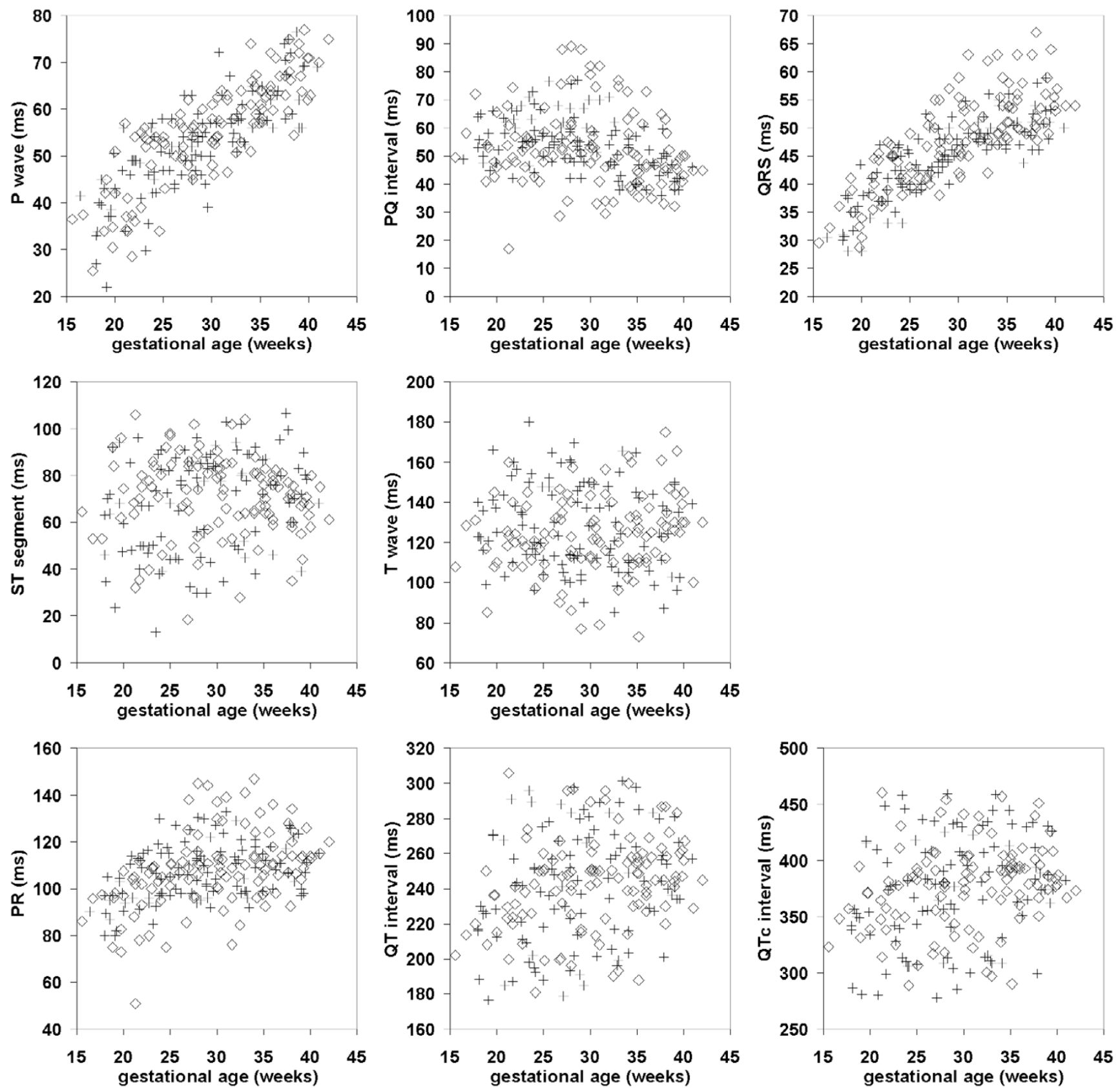

Figure 3

Scatter plots of fetal CTI vs. gestational age Duration of CTI with respect to gestational age: disjunct intervals ( $P$ wave, $\mathrm{PQ}$ interval, QRS complex, ST segment, T wave) in the top two rows, composite intervals (PR, QT and QTc interval) in the bottom row (males $\diamond$, females + ).

extended gestational periods. Thus a realistic estimation of their duration can be made independently of age.

The distinct relationship between depolarization times and age has often been posited to reflect changes in heart size over gestation [e.g. [8]]: the larger the cardiac chambers, the more time needed for the depolarization wave to travel over the myocardium. Indeed, mammalian hearts display a dependency on body mass with respect to organ size and conduction time [21]. The weight of the fetal 
Table I: CTI dependency on gestational age. Dependency of fetal cardiac time intervals on gestational age (in weeks): coefficients of determination $\left(r^{2}\right), y$-intercepts, slopes and the $p$-value of the slopes (values $<.05$ in bold type). Linear regression parameters are given for each disjunct interval (upper rows) and each composite interval (lower rows). Non-linear regression parameters are also given for those intervals in which an improved model fit was found (quadratic: PQ and PR interval, double logarithmic: QRS complex).

\begin{tabular}{|c|c|c|c|c|c|c|c|c|}
\hline & $\begin{array}{l}\text { regression } \\
\text { type }\end{array}$ & $N$ & $r^{2}$ & $\begin{array}{c}y \text {-intercept } \\
\text { (ms) }\end{array}$ & slope (ms/week) & $p$ & slope (ms/week $\left.{ }^{2}\right)$ & $p$ \\
\hline$P$ wave & linear & 228 & 0.67 & 14.0 & 1.37 & $<0.001$ & & \\
\hline$P Q$ interval & linear & 228 & 0.07 & 67.7 & -0.49 & $<0.001$ & & \\
\hline$P Q$ interval & non-linear & 228 & 0.13 & 14.2 & 3.38 & 0.021 & -0.07 & 0.008 \\
\hline QRS complex & linear & 230 & 0.62 & 19.3 & 0.92 & $<0.001$ & & \\
\hline $\ln (\mathrm{QRS})$ & non-linear & 230 & 0.66 & 1.8 & $0.60 *$ & $<0.001$ & & \\
\hline ST segment & linear & 217 & 0.01 & 60.4 & 0.32 & 0.169 & & \\
\hline T wave & linear & 216 & 0.00 & 126.0 & 0.00 & 1.000 & & \\
\hline PR interval & linear & 228 & 0.16 & 81.7 & 0.88 & $<0.001$ & & \\
\hline PR interval & non-linear & 228 & 0.21 & 20.0 & 5.35 & $<0.001$ & -0.08 & 0.002 \\
\hline QT interval & linear & 216 & 0.07 & 205.8 & 1.24 & $<0.001$ & & \\
\hline QTc interval & linear & 216 & 0.06 & 326.6 & 1.65 & $<0.001$ & & \\
\hline
\end{tabular}

* the slope in this regression equation is $\mathrm{ms} / \ln ($ week)

Table 2: Weekly values for $P, P Q$ and $P R$ Estimated value for the $P$ wave, $P Q$ interval and $P R$ interval and their respective $90 \%$ prediction interval (PI) based on each interval's best fitting regression model. Values from the $17^{\text {th }}$ to the $42^{\text {nd }}$ week are given. $\mathrm{N}$ is the number of case avaliable for the model in any respective week.

\begin{tabular}{|c|c|c|c|c|}
\hline Gestational age week & $N$ & $\begin{array}{c}P \text { wave }(\mathrm{ms}) \text { estimated value } \\
(90 \% \mathrm{Pl})\end{array}$ & $\begin{array}{c}\text { PQ interval }(\mathrm{ms}) \text { estimated } \\
\text { value }(90 \% \mathrm{Pl})\end{array}$ & $\begin{array}{c}\text { PR interval }(\mathrm{ms}) \text { estimated } \\
\text { value }(90 \% \mathrm{Pl})\end{array}$ \\
\hline 17 & I & $37(27-48)$ & $52(34-7 I)$ & $89(67-110)$ \\
\hline 18 & 5 & $39(28-49)$ & $54(35-72)$ & $91(70-113)$ \\
\hline 19 & 8 & $40(30-50)$ & $54(36-73)$ & $94(73-115)$ \\
\hline 20 & 9 & $4 I(31-52)$ & $55(37-74)$ & $96(75-117)$ \\
\hline 21 & 8 & $43(32-53)$ & $56(38-74)$ & $98(77-119)$ \\
\hline 22 & 9 & $44(34-55)$ & $56(38-75)$ & $100(80-121)$ \\
\hline 23 & 12 & $45(35-56)$ & $57(39-75)$ & $102(81-123)$ \\
\hline 24 & 10 & $47(36-57)$ & $57(39-75)$ & $104(83-125)$ \\
\hline 25 & 9 & $48(38-59)$ & $57(39-75)$ & $106(85-127)$ \\
\hline 26 & 8 & $50(39-60)$ & $57(39-75)$ & $107(86-128)$ \\
\hline 27 & 11 & $5 I(4 I-6 I)$ & $57(39-75)$ & $108(88-129)$ \\
\hline 28 & 16 & $52(42-63)$ & $57(38-75)$ & $110(89-130)$ \\
\hline 29 & 11 & $54(43-64)$ & $56(38-75)$ & $111(90-131)$ \\
\hline 30 & 12 & $55(45-65)$ & $56(38-74)$ & $111(90-132)$ \\
\hline 31 & 7 & $56(46-67)$ & $55(37-73)$ & $112(91-133)$ \\
\hline 32 & 10 & $58(47-68)$ & $54(36-73)$ & $112(92-133)$ \\
\hline 33 & 11 & $59(49-70)$ & $53(35-72)$ & $113(92-134)$ \\
\hline 34 & 9 & $6 I(50-71)$ & $52(34-7 I)$ & $113(92-134)$ \\
\hline 35 & 12 & $62(52-72)$ & $51(33-69)$ & $113(92-134)$ \\
\hline 36 & 10 & $63(53-74)$ & $50(31-68)$ & $113(92-134)$ \\
\hline 37 & 6 & $65(54-75)$ & $48(30-67)$ & $113(92-134)$ \\
\hline 38 & 14 & $66(56-76)$ & $47(28-65)$ & $112(91-133)$ \\
\hline 39 & 9 & $67(57-78)$ & $45(26-63)$ & $112(91-133)$ \\
\hline 40 & 6 & $69(58-79)$ & $43(25-62)$ & $111(90-132)$ \\
\hline 41 & 2 & $70(60-81)$ & $41(22-60)$ & $110(89-131)$ \\
\hline 42 & I & $72(61-82)$ & $39(20-58)$ & $109(88-131)$ \\
\hline
\end{tabular}


Table 3: Weekly values for QRS. Estimated value for the QRS complex (all, female and male data) and their respective $90 \%$ prediction interval (PI) based on the best fitting regression model. Values from the $17^{\text {th }}$ to the $42^{\text {nd }}$ week are given. $\mathrm{N}$ is the number of cases available for the model in any respective week. $p$ values comparing the female and male $Q R S$ durations are given showing the transition to statistically distinguishable values at the $3 I^{\text {st }}$ week ( $p$ values $<.05$ in bold type).

\begin{tabular}{|c|c|c|c|c|c|c|c|}
\hline $\begin{array}{l}\text { Gestational age } \\
\text { week }\end{array}$ & $N$ & $\begin{array}{l}\text { QRS all }(\mathrm{ms}) \text { estimated } \\
\text { value }(90 \% \mathrm{PI})\end{array}$ & $N$ & $\begin{array}{c}\text { QRS female }(\mathrm{ms}) \\
\text { estimated value }(90 \% \mathrm{PI})\end{array}$ & $N$ & $\begin{array}{l}\text { QRS male }(\mathrm{ms}) \\
\text { estimated value }(90 \% \mathrm{PI})\end{array}$ & $P$ \\
\hline 17 & I & $33(28-40)$ & & $30(24-37)$ & 1 & $34(29-4 I)$ & \\
\hline 18 & 5 & $35(29-4 I)$ & 4 & $32(26-39)$ & 1 & $35(30-42)$ & \\
\hline 19 & 8 & $36(30-42)$ & 5 & $34(28-4 I)$ & 3 & $37(31-44)$ & \\
\hline 20 & 9 & $37(31-44)$ & 5 & $36(30-42)$ & 4 & $38(32-45)$ & \\
\hline 21 & 8 & $38(32-45)$ & 3 & $38(32-44)$ & 5 & $39(33-46)$ & \\
\hline 22 & 9 & $39(33-46)$ & 5 & $39(33-45)$ & 4 & $40(34-48)$ & \\
\hline 23 & 13 & $40(34-47)$ & 7 & $40(34-46)$ & 6 & $4 I(34-49)$ & \\
\hline 24 & 11 & $4 \mathrm{I}(35-49)$ & 8 & $4 I(35-48)$ & 3 & $42(35-50)$ & \\
\hline 25 & 9 & $42(36-50)$ & 4 & $43(36-49)$ & 5 & $43(36-5 I)$ & 0.576 \\
\hline 26 & 8 & $43(37-5 I)$ & 6 & $44(37-50)$ & 2 & $44(37-53)$ & 0.537 \\
\hline 27 & 11 & $44(37-52)$ & 5 & $44(38-51)$ & 6 & $45(38-54)$ & 0.467 \\
\hline 28 & 16 & $45(38-53)$ & 8 & $45(39-51)$ & 8 & $46(39-55)$ & 0.335 \\
\hline 29 & 11 & $46(39-54)$ & 9 & $46(40-52)$ & 2 & $47(40-56)$ & 0.211 \\
\hline 30 & 12 & $47(40-55)$ & 4 & $47(4 I-53)$ & 8 & $48(40-57)$ & 0.100 \\
\hline 31 & 7 & $48(4 I-57)$ & 1 & $48(4 I-54)$ & 6 & $49(4 I-58)$ & 0.034 \\
\hline 32 & 10 & $49(4 I-58)$ & 5 & $48(42-54)$ & 5 & $50(42-59)$ & 0.009 \\
\hline 33 & II & $50(42-59)$ & 8 & $49(43-55)$ & 3 & $5 I(43-6 I)$ & 0.001 \\
\hline 34 & 9 & $51(43-60)$ & 3 & $49(43-55)$ & 6 & $52(43-62)$ & $<0.001$ \\
\hline 35 & 12 & $52(44-6 I)$ & 3 & $50(44-56)$ & 9 & $53(44-63)$ & $<0.001$ \\
\hline 36 & 10 & $52(44-62)$ & 3 & $50(44-57)$ & 7 & $54(45-64)$ & $<0.001$ \\
\hline 37 & 6 & $53(45-63)$ & 4 & $51(45-57)$ & 2 & $54(46-65)$ & $<0.001$ \\
\hline 38 & 14 & $54(46-64)$ & 6 & $51(45-57)$ & 8 & $55(46-66)$ & $<0.001$ \\
\hline 39 & 9 & $55(47-65)$ & 5 & $52(46-58)$ & 4 & $56(47-67)$ & $<0.001$ \\
\hline 40 & 6 & $56(47-66)$ & 1 & $52(46-58)$ & 5 & $57(48-68)$ & \\
\hline 41 & 2 & $57(48-67)$ & 1 & $53(46-59)$ & 1 & $58(48-69)$ & \\
\hline 42 & 1 & $58(49-68)$ & & $53(47-59)$ & 1 & $59(49-70)$ & \\
\hline
\end{tabular}

Table 4: Values for ST, T and QT. Measures of location for those intervals demonstrating no dependency on gestational age.

\begin{tabular}{|c|c|c|c|c|c|c|c|}
\hline & & $\mathrm{N}$ & minimum & $5^{\text {th }}$ percentile & median & $95^{\text {th }}$ percentile & maximum \\
\hline ST segment & (ms) & 217 & 13 & 35 & 72 & 96 & 107 \\
\hline T wave & (ms) & 216 & 73 & 96 & 124 & 160 & 180 \\
\hline QT interval & (ms) & 216 & 176 & 192 & 245 & 290 & 306 \\
\hline QTc interval & (ms) & 216 & 278 & 300 & 380 & 443 & 460 \\
\hline
\end{tabular}

Table 5: CTI dependency on biometric data. Dependency of $P$ wave and QRS (determined $\leq 7$ days before birth) on birth weight, crownheel length and head circumference at birth

\begin{tabular}{ccccccc}
\hline & & $N$ & $r^{2}$ & intercept & slope \\
\hline \multirow{2}{*}{ birth weight $(\mathrm{g})$} & P wave & 15 & 0.01 & 64.6 & 0.0010 & 0.768 \\
& QRS complex & 15 & 0.08 & 43.7 & 0.0029 & 0.198 \\
crown-heel length $(\mathrm{cm})$ & P wave & 14 & 0.06 & 98.5 & -0.589 & 0.303 \\
& QRS complex & 14 & 0.08 & 27.7 & 0.490 & 0.143 \\
head circumference $(\mathrm{cm})$ & P wave & 14 & 0.16 & 10.9 & 1.63 & 0.113 \\
& QRS complex & 14 & 0.27 & -2.0 & 1.57 & 0.067 \\
\hline
\end{tabular}


heart has been shown increase over time both with respect to body weight and gestational age [22] and estimations of fetal cardiac dimensions and mass based on ultrasound recording show a steady increase over time [23-25]. The estimation of these dependencies are, more often than not, described more adequately using quadratic polynomials than a linear model. This reflects the slowing of the increase in size with a concomitant higher variance towards the end of pregnancy. With respect to the change of QRS duration over time, we found a similar trend in the data and, consequently, that nonlinear models fitted more appropriately. This has also been noted by others on the basis of fetal ECG data $[9,26]$ and further supports the notion of the link between fetal cardiac dimension and interval duration.

We compared representative CTI values in the terminal period of pregnancy, based on our data, to neonatal and infant PR, QRS and QT times found in the literature $[27,28]$. These showed a high degree of agreement for the duration of AV conduction and ventricular depolarization. With respect to the T wave, the FMCG measures of location were lower than those reported for the newborns. This may be attributed to the rate dependency of the QT times, as the prepartal heart rate is higher than postpartal. Another reason for the difference may be the difficulty in the determination of the FMCG T wave, its low amplitude waveform shape leading to underestimation of its length.

On the basis of our findings, one further factor leading to the greater variance of QRS duration towards the end of pregnancy can be presumed to be fetal gender: a trend to lower values for females was distinguishable after the $30^{\text {th }}$ week. Gender based differences in QRS duration have also been noted by Brambati and Pardi [9], albeit not statistically significant. Furthermore, in pediatric populations, QRS duration has been shown to be shorter in girls than in boys $[28,29]$. Females are characterized by a lower birth weight than males, in particularly at later gestational ages [30]. This trend was also present in our subjects (males $3716 \pm 555 \mathrm{~g}$, females $3438 \pm 497 \mathrm{~g}$, $\mathrm{p}=0.088$ ). In the light of the above, the trend to shorter female QRS duration may correspond at least in part to their lower body weight. This fact will be of importance, for example, when investigating the possible association between growth retardation and CTI $[17,20]$ in order to avoid masking reduced QRS duration in male subjects.

The results with respect to biometric data were inconclusive: only head circumference displayed a weak relationship to QRS duration. This was surprising, in particular for birth weight, as such a dependency has been reported in a larger collective [9]. One of the reasons for the lack of correlation in our data may have been due to the fact that only 15 FMCG recordings performed within one week of birth were available for analysis. Furthermore, the relationships between fetal depolarization times, heart size and body weight discussed above are largely based on longitudinal studies. Examining the relationship on a cross section of subjects within a narrow range of time at the end of pregnancy when most biometric values are stabilizing will make the identification of a trend difficult and will likely require a substantial number of cases. It is however interesting to note that head circumference, which showed a weak correlation to QRS, has been identified as being more reliable than other biometric parameters in the estimation of fetal age $[31,32]$.

The overall high number of FMCG recordings permitted a reliable statistical description of the data with respect to the gestational period observed. However, the results are limited by the moderate number per week of gestation (ca. [10]). We did not deem this enough to give a stable description per week and we preferred instead to extrapolate weekly values on the basis of regression analysis parameters. A higher number of subjects and recordings would alleviate this limitation. Another aspect which must be kept in mind is that the precise determination of gestational age is a prerequisite for the correct estimation of dependency. We established gestational age as the computed interval between the date of last normal menses and the date of recording. Although other measures exist [33], we chose this procedure as it is commonly used and we did not always have access to ultrasound biometrics or other documentation.

\section{Conclusions}

In summary, we may conclude that fetal CTI which quantify depolarization times can be reliably determined using FMCG from approximately the $18^{\text {th }}$ week to term, that P wave and QRS complex duration show a high dependency on age which to a large part reflects fetal growth and that fetal gender plays a role in QRS complex duration. Fetal development is thus reflected in the CTI and may be useful in the identification of pathological states such as intrauterine growth retardation.

\section{Competing interests}

None declared.

\section{Authors' contributions}

PVL and SL designed the study. PVL, SL and AK recruited the subjects, collected the data and did the signal processing. DG developed the software for the data handling. SL performed the statistical analysis. PVL, SL, AK and DG participated in the analysis of the results. PVL drafted the manuscript. All authors were involved in the interpretation of the data and participated in the final revision. 


\section{References}

I. Quinn A, Weir A, Shahani U, Bain R, Maas P, Donaldson G: Antenatal fetal magnetocardiography: a new method for fetal surveillance? Br J Obstet Gynaecol 1994, I 01 :866-870

2. Van Leeuwen $P$, Schüßler M, Bettermann H, Lange S, Hatzmann W: Magnetocardiography for assessment of fetal heart actions. Geburtshilfe Frauenheilkd 1995, 55:642-646.

3. Menendez T, Achenbach S, Moshage W, Flüg M, Beinder E, Kollert A Bittel A, Bachmann K: Prenatal recording of fetal heart action with magnetocardiography. Z Kardiol 1998, 87: I I I- I I8.

4. Leuthold A, Wakai RT, Martin CB: Noninvasive in utero assess ment of PR and QRS intervals from the fetal magnetocardiogram. Early Hum Dev 1999, 54:235-243.

5. Horigome H, Takahashi MI, Asaka M, Shigemitsu S, Kandori A, Tsukada K: Magnetocardiographic determination of the developmental changes in PQ, QRS and QT intervals in the foetus. Acta Paediatr 2000, 89:64-67.

6. Kähler C, Schleussner E, Grimm B, Schneider A, Schneider U, Nowak $\mathrm{H}$, Seewald HJ: Fetal magnetocardiography: development of the fetal cardiac time intervals. Prenat Diagn 2002, 22:408-4|4.

7. Lowery CL, Campbell JQ, Wilson JD, Murphy P, Preissl H, Malak SF Eswaran $\mathrm{H}$ : Noninvasive antepartum recording of fetal S-T segment with a newly developed I 5 I-channel magnetic sensor system. Am J Obstet Gynecol 2003, I 88: |49| - |496.

8. Stinstra J, Golbach E, van Leeuwen P, Lange S, Menendez T, Moshage W, Schleussner E, Kaehler C, Horigome H, Shigemitsu S, Peters MJ: Multicentre study on the fetal cardiac time intervals using magnetocardiography. BJOG 2002, 109: 1235-43.

9. Brambati $B$, Pardi $G$ : The intraventicular conduction time of fetal heart in uncomplicated pregnancies. Br J Obstet Gynaecol 1980, 87:94|-949.

10. Van Leeuwen P, Lange S, Klein A, Geue D, Zhang Y, Krause HJ, Grönemeyer D: Reproducibility and reliability of fetal cardiac time intervals using magnetocardiography. Physiol Meas 2004, 25:539-552

II. Grimm B, Haueisen J, Huotilainen M, Lange S, Van Leeuwen P, Menendez T, Peters MJ, Schleussner E, Schneider U: Recommended standards for fetal magnetocardiography. PACE 2003 26:2| $2|-2| 26$

12. Wakai RT, Leuthold AC, Wilson AD, Martin CB: Association of fetal junctional rhythm and respiratory arrhythmia detected by magnetocardiography. Pediatr Cardiol I997, I 8:201-203

13. Van Leeuwen P, Hailer B, Bader W, Geissler J, Trowitzsch E, Grönemeyer DHW: Magnetocardiography in the diagnosis of feta arrhythmia. Br J Obstet Gynaecol 1999, I 06: I 200-I 208.

14. Menendez T, Achenbach S, Beinder E, Hofbeck M, Schmid O, Singer H, Moshage W, Daniel WG: Prenatal diagnosis of QT prolongation by magnetocardiography. PACE 2000, 23:1305-I307.

15. Quartero HW, Stinstra JG, Golbach EG, Meijboom El, Peters MJ: Clinical implications of fetal magnetocardiography. Ultrasound Obstet Gynecol 2002, 20:142-I53.

16. Kähler C, Grimm B, Schleussner E, Schneider A, Schneider U, Nowak $H$, Vogt L, Seewald HJ: The application of fetal magnetocardiography (FMCG) to investigate fetal arrhythmias and congenital heart defects (CHD). Prenat Diagn 200I, 2 I: I76-182.

17. Van Leeuwen P, Lange S, Hackmann J, Klein A, Hatzmann W, Grönemeyer $D$ : Assessment of intra-uterine growth retardation by fetal magnetocardiography. In Biomag Proc 12th Int Conf on Biomagnetism: 13-I 7 August 2000; Helsinki Edited by: Nenonen J, Ilmoniemi RJ, Katila T. Espoo Helsinki Univ Technology; 2001:603-606.

18. Bazett HC: An analysis of the time-relations of electrocardiograms. Heart 1920, 7:353-370.

19. Williams RL: A note on robust variance estimation for cluster correlated data. Biometrics 2000, 56:645-646.

20. Van Leeuwen P, Klein A, Lange S, Böhle K, Hatzmann W, Grönemeyer $D$ : Changes in cardiac time intervals in growth retarded fetuses as determined by fetal magnetocardiography. IFMBE Proc 2002, 3: I524- 1525.

21. Meijler FL: Atrioventricular conduction versus heart size from mouse to whale. J Am Coll Cardiol 1985, 5:363-365.

22. Guihard-Costa AM, Menez F, Delezoide AL: Organ Weights in Human Fetuses after Formalin Fixation. Pediatr Dev Pathol 2002, 5:559-578

23. St John Sutton MG, Gewitz MH, Shah B, Cohen A, Reichek N, Gabbe S, Huff DS: Quantitative assessment of growth and function of the cardiac chambers in the normal human fetus: a prospec- tive longitudinal echocardiographic study. Circulation 1984 69:645-654

24. Shapiro I, Degani S, Leibovitz Z, Ohel G, Tal Y, Abinader EG: Fetal cardiac measurements derived by transvaginal and transabdominal cross-sectional echocardiography from I 4 weeks of gestation to term. Ultrasound Obstet Gynecol 1998, I 2:404-4I 8.

25. Firpo C, Hoffman II, Silverman $\mathrm{NH}$ : Evaluation of fetal heart dimensions from 12 weeks to term. Am J Cardiol 200I, 87:594-600

26. Taylor MJ, Smith MI, Thomas M, Green AR, Cheng F, Oseku-Afful S, Wee LY, Fisk NM, Gardiner HM: Non-invasive fetal electrocardiography in singleton and multiple pregnancies. BJOG 2003, I l 0:668-678.

27. Davignon A, Rautaharju P, Boiselle E, Soumis F, Megelas M, Choquette A: Normal ECG standards for infants and children. Pediat Cardiol 1979, I:I23-I52.

28. Rijnbeek PR, Witsenburg M, Schrama E, Hess J, Kors JA: New normal limits for the paediatric electrocardiogram. Eur Heart 200I, 22:702-7II.

29. Vaksmann G, Elkohen M, Duhamel A, Godart F: Signal-averaged electrocardiography in healthy children: influence of age, body size, and gender. PACE 1996, 19:1629-1634.

30. Alexander GR, Kogan MD, Himes JH: 1994-1996 U.S. singleton birth weight percentiles for gestational age by race, Hispanic origin, and gender. Matern Child Health J I999, 3:225-23 I.

3I. Hadlock FP, Deter RL, Harrist RB, Park SK: Estimating fetal age: computer-assisted analysis of multiple fetal growth parameters. Radiology I984, I 52:497-50 I.

32. Nahum GG, Stanislaw H: Ultrasonographic prediction of term birth weight: how accurate is it? Am J Obstet Gynecol 2003, I 88:566-574.

33. O'Rahilly R, Muller F: Prenatal ages and stages-measures and errors. Teratology 2000, 6 I:382-384

\section{Pre-publication history}

The pre-publication history for this paper can be accessed here:

\section{http://www.biomedcentral.com/1471-2393/4/6/prepub}

Publish with Bio Med Central and every scientist can read your work free of charge

"BioMed Central will be the most significant development for disseminating the results of biomedical research in our lifetime. "

Sir Paul Nurse, Cancer Research UK

Your research papers will be:

- available free of charge to the entire biomedical community

- peer reviewed and published immediately upon acceptance

- cited in PubMed and archived on PubMed Central

- yours - you keep the copyright

Submit your manuscript here:

http://www.biomedcentral.com/info/publishing_adv.asp
BioMedcentral 